\title{
Derivation of the out-of-plane behaviour of an English bond masonry wall through homogenization strategies
}

\author{
Luís Carlos Silva ${ }^{1, a)}$, Gabriele Milani' ${ }^{2, b)}$, Paulo B. Lourenço ${ }^{3, c)}$ \\ ${ }^{1}$ PhD Candidate, Dept. of Civil Engineering, ISISE, University of Minho, Azurém, 4800-058 Guimarães, Portugal. \\ ${ }^{2}$ Associate Professor, Dept. of Architecture, Built environment and Construction engineering (A.B.C.), Technical \\ University in Milan, Piazza Leonardo da Vinci 32, 20133 Milan, Italy. \\ ${ }^{3}$ Full Professor, Dept. of Civil Engineering, ISISE, University of Minho, Azurém, 4800-058 Guimarães, Portugal.
}

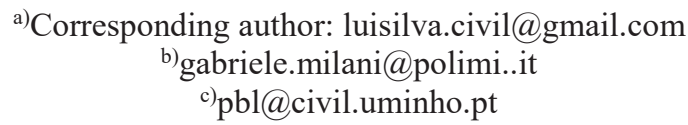

\begin{abstract}
Two finite element homogenized-based strategies are presented for the out-of-plane behaviour characterization of an English bond masonry wall. A finite element micro-modelling approach using Cauchy stresses and first order movements are assumed for both strategies. The material nonlinearity is lumped on joints interfaces and bricks are considered elastic. Nevertheless, the first model is based on a Plane-stress assumption, in which the out-of-plane quantities are derived through on-thickness wall integration considering a Kirchhoff-plate theory. The second model is a tridimensional one, in which the homogenized out-of-plane quantities can be directly derived after solving the boundary value problem. The comparison is conducted by assessing the obtained out-of-plane bending- and torsion-curvature diagrams. A good agreement is found for the present study case.
\end{abstract}

\section{INTRODUCTION}

Unreinforced masonry (URM) buildings typically present low resistance to out-of-plane loads [1]. Both masonry texture and components size may vary. So, if one aims to characterize the out-of-plane behaviour of masonry, thorough and expensive experimental campaigns may be needed. In this way, numerical methods can be an important asset to overcome such drawback and drive to a better insight on this matter.

It is noteworthy the efforts made in the last decades on the numerical out-of-plane analysis of masonry structures. Nowadays, the use of more complex ones as the classical finite-element (FE) based methods are well spread. These are generally designated as micro- or macro- [2]. The former method considers masonry as a fictitious homogeneous material and thus does not distinct masonry components (units and joints). In the latter method, the micro-structure of masonry is performed, meshing bricks and mortar separately. Nevertheless, fully representing the masonry arrangement through micro-FE models can be time consuming and require a high computational effort. In this regard, homogenization or multi-scale FE methods, which are in-between with these two modelling FE schemes, may overcome this issue [3]. Homogenization is essentially an averaging procedure performed at a meso-scale on a representative element of volume (RVE), which generates the masonry pattern by repetition. Still, research tend to focus mainly on the study of running-bond masonry pattern [4-6].

The present work tries to contribute for a better understanding of the out-of-plane behaviour of an English bond masonry wall. Two homogenization-based strategies are presented. The methodologies aim to characterize such behaviour through the derivation of homogenized out-of-plane bending and torsional moment-curvature curves. It may be stressed that this information is specially drawn to serve as input for simplified strategies at a structural scale (see [7] for an application for running-bond pattern). The ad-hoc models herein compared are computed in the commercial software DIANA[8]. 


\section{OUT-OF-PLANE HOMOGENIZED MODELS}

\section{Overview}

Two homogenized-based approaches are following presented for the out-of-plane characterization of an English bond masonry wall. Such strategy lies on the periodicity feature of a given media and it is therefore a suitable strategy for masonry [9]. In brief, homogenization consists in deriving the upper-scale properties by introducing averaged quantities for macroscopic quantities obtained at a micro-scale on the RVE (Y is the elementary cell, Fig.1). In this study, full FE-based models are referred. Two methodologies are following presented. For the sake of conciseness, these are designated as (i) Simplified Homogenized model (SH model); and (ii) tridimensional homogenized model (TH model). The RVE definition is in accordance with the recommended in [10] for the English bond pattern. Figure 1 shows a schematic representation of the assumed RVE and of the two frameworks. Both are based on a simplified micro-modelling approach. Damage and material constitutive models adopted are well studied in the literature and particularly suitable for masonry structures [11]. The case study material properties are: (i) for masonry, the Young modulus and Poisson coefficient is 10,000 $\mathrm{MPa}$ and 0.2 , respectively; (ii) for mortar, the Young modulus is $2,200 \mathrm{MPa}$; the Poisson coefficient is 0.25 ; the cohesion is $0.2 \mathrm{MPa}$; the internal friction angle is 30 degrees; the tensile strength is $0.105 \mathrm{MPa}$; the mode-I and mode-II facture energy are $0.012 \mathrm{~N} / \mathrm{mm}$ and 0.05 $\mathrm{N} / \mathrm{mm}$, respectively; the compressive strength is $2.85 \mathrm{MPa}$ and the compressive fracture energy is $3.9 \mathrm{~N} / \mathrm{mm}$.

MACRO-SCALE

MESO-SCALE

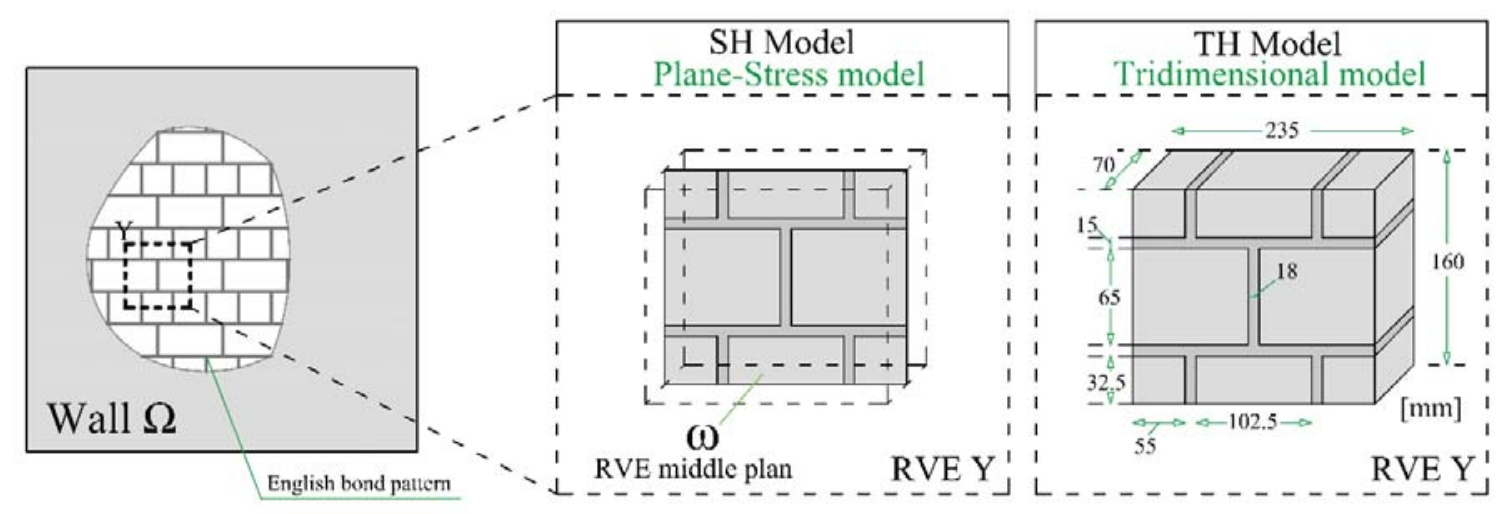

FIGURE 1. Representative Volume Element (RVE) adopted for the SH and TH model at a meso-scale.

\section{Simplified Homogenized (SH) model}

The first adopted strategy relies on an in-plane homogenization technique. The homogenized $\Sigma$ and $\mathrm{E}$ quantities are firstly obtained through a simplified FE micro-modelling approach. The imposition of three fundamental deformation modes is assumed: (i) mode-I, for the horizontal direction; (ii) mode-I, for the vertical direction and (iii) mode-II, see Fig. 2. Bricks are discretized by means of plane-stress quadrilateral elements with linear interpolation and joints by zero-thickness line interfaces. It is assumed that all the nonlinearity is lumped on joints. This assumptions seems to be adequate once: (i) there is an absence of any pre-compression state so, cracking or crushing of bricks is unlikely to happen; (ii) seems in agreement with experimental data, in which crack onset and propagation tend to follow a zigzag along joints and between bricks [12]. The latter assumption is specially observed for the cases of strong block masonry structures, as the one studied.

A multisurface plasticity model from [11] is considered for the interface elements. This material model is able to simulate fracture, frictional slip and crushing along the interface elements. The constitutive interface model is defined by a convex composite yield criterion with three individual yield functions, i.e. tensile, shear and compressive criterion [11]. The response of the RVE under out-of-plane actions is simply obtained by on-thickness integration of the quantities $\boldsymbol{\Sigma}=\left[\begin{array}{lll}\Sigma_{11} & \Sigma_{22} & \Sigma_{12}\end{array}\right]^{T}$ through a Kirchhoff-plate theory. 


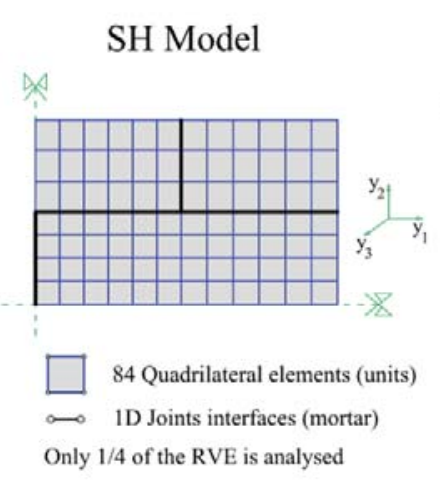

(a)

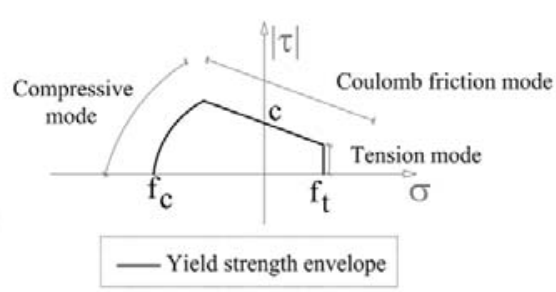

Multisurface interface model for mortar joints

(b)

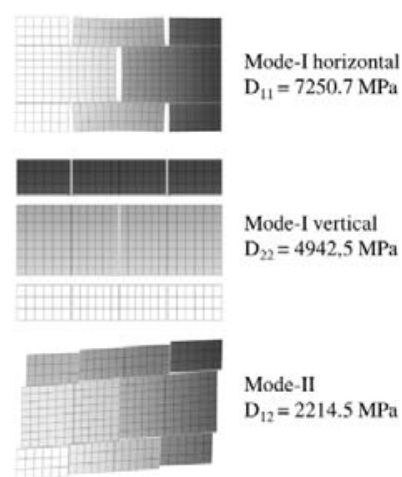

(c)

FIGURE 2. Simplified Homogenized (SH) model: (a) A quarter of the studied FE micro-model; (b) Multisurface interface model adopted for mortar joints by [11]; (c) Deformation modes assumed and in-plane RVE elastic identification.

\section{Tridimensional Homogenized (TH) model}

The second strategy to derive the bending- and torsion-curvature curves relies on a tridimensional model. It follows similar assumptions of the SH model: (i) a simplified micro-modelling is used whereas mortar joints concentrate all the material nonlinearity; (ii) the extension of the two-dimensional interface model is used to deal with the tridimensional interfaces (see [13]); and (iii) volume brick elements with linear interpolation are used for the elastic bricks. For the sake of simplicity, according to the deformation modes considered (Fig. 3), the bending and torsional curve values are directly obtained by applying curvature increments $\chi$ at the boundary surfaces.

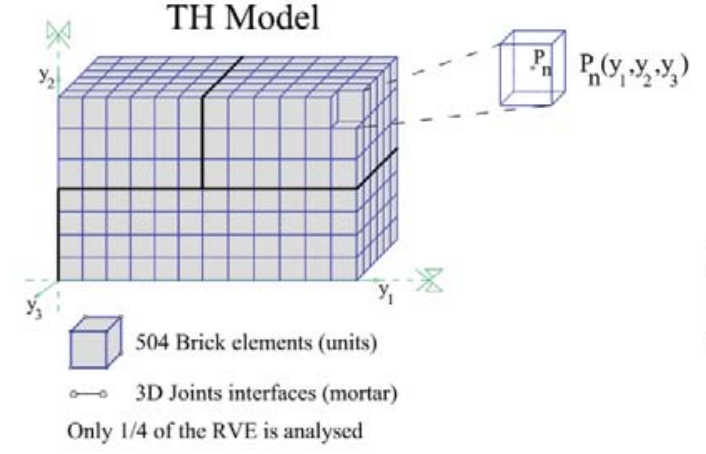

(a)

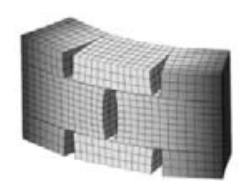

$\mathrm{M}_{11}$

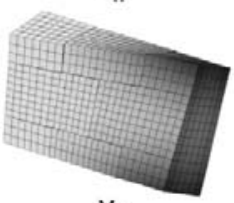

$\mathrm{M}_{21}$

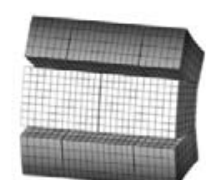

$\mathrm{M}_{22}$

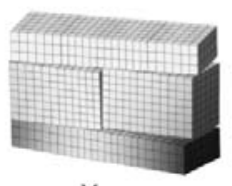

$\mathrm{M}_{12}$

(b)

FIGURE 3. Tridimensional Homogenized (TH) model: (a) A quarter of the studied FE micro-model; (b) Deformation modes assumed.

\section{ACKNOWLEDGEMENTS}

This work was supported by FCT (Portuguese Foundation for Science and Technology), within ISISE, scholarship SFRH/BD/95086/2013. This work was also partly financed by FEDER funds through the Competitivity Factors Operational Programme - COMPETE and by national funds through FCT - Foundation for Science and Technology within the scope of the project POCI-01-0145-FEDER-007633.

\section{REFERENCES}

1. Spence R, Coburn A. Strengthening building of stone masonry to resist earthquakes. Meccanica. 1992;27:213-21. 
2. Lourenço PB. Structural masonry analysis : recent developments and prospects. In: Proceedings of the 14th International brick and block masonry conference. Sydney: University of Newcastle, Australia; 2008.

3. Luciano R, Sacco E. Homogenization technique and damage model for old masonry material. Int J Solids Struct. 1997 Aug;34(24):3191-208.

4. Cecchi A, Milani G, Tralli A. A Reissner-Mindlin limit analysis model for out-of-plane loaded running bond masonry walls. Int J Solids Struct. 2007;44(5):1438-60.

5. Milani G, Lourenço PB, Tralli A. Homogenized rigid-plastic model for masonry walls subjected to impact. Int J Solids Struct. 2009;46(22):4133-49.

6. Massart TJ, Peerlings RHJ, Geers MGD. An enhanced multi-scale approach for masonry wall computations with localization of damage. Int J Numer Methods Eng [Internet]. 2007 Jan 29 [cited 2016 Jul 25];69(5):1022-59. Available from: http://doi.wiley.com/10.1002/nme.1799

7. Silva LC, Lourenço PB, Milani G. Nonlinear Discrete Homogenized Model for Out-of-Plane Loaded Masonry Walls. J Struct Eng [Internet]. 2017 Sep [cited 2017 May 28];143(9). Available from: http://ascelibrary.org/doi/10.1061/\%28ASCE\%29ST.1943-541X.0001831

8. $\quad$ DIANA. User's manual. BV, Delft, The Netherlands: Release 9.4.4, TNO DIANA; 2010.

9. Pegon $\mathrm{P}$, Anthoine A. Numerical strategies for solving continuum damage problems with softening: Application to the homogenization of Masonry. Comput Struct. 1997 Jul;64(1-4):623-42.

10. Anthoine A. Derivation of the in-plane elastic characteristics of masonry through homogenization theory. Int J Solids Struct. 1995 Jan;32(2):137-63.

11. Lourenço PB, Rots JG. Multisurface Interface Model for Analysis of Masonry Structures. J Eng Mech. 1997 Jul 1;123(7):660-8.

12. Herbert DM, Gardner DR, Harbottle M, Hughes TG. Uniform lateral load capacity of small-scale masonry wall panels. Mater Struct [Internet]. 2014 May 12 [cited 2017 Mar 28];47(5):805-18. Available from: http://link.springer.com/10.1617/s11527-013-0092-7

13. Zijl, Van GPAG. Computational Modelling of Masonry Creep and Shrinkage. Delft University of Technology; 2000. 